\title{
Effect of Kegel Exercise on Vital Capacity According to the Position: A Preliminary Study
}

\author{
KangHui Park, HanKyu Park \\ Department of Physical Therapy, Dong ju College, Busan, Republic of Korea
}

Purpose: This study examined the immediate effect of Kegel exercise on the vital capacity according to the position.

Methods: Seventeen subjects participated in the study (male $=7$, female $=10$ ). The subjects performed Kegel exercise in two positions: sitting and hooklying. The order of exercise was conducted in a random order selected by the subjects to exclude the learning effect. The maximum voluntary ventilation (MW) was measured using a spirometer. The vital capacity was measured according to the manual in the sitting position before the experiment. After each exercise, the vital capacity was also measured in the same way. One way repeated measures analysis of the variance (ANOVA) was used to compare the vital capacity according to the position, and a Bonferroni test was used for post hoc analysis.

Results: Significant differences in vital capacity were observed after exercise than before exercise $(p<0.05)$. Post-hoc analysis, however, revealed no difference in vital capacity according to the position ( $p>0.05)$.

Conclusion: This study was a preliminary study to determine the vital capacity according to the Kegel exercise and two positions. Nevertheless, further study with several revisions of the number of subjects, duration, and time for intervention will be needed.

Keywords: Kegel exercise, Vital capacity, Position

\section{서 론}

1948년 케겔 박사가 처음으로 제안한 케겔 운동(Kegel exercise)은 골 반바닥근의 약화로 인하여 발생하는 비뇨기계 질환(urinary system diseases)의 대표적인 요실금(urinary incontinence) 환자들을 치료하는 운동방법으로 골반바닥근(pelvic floor muscle)의 수축을 통해서 요실 금을 해결하는 방법 중 하나로 널리 사용되어져 왔다. ${ }^{1,2}$ 케겔 운동은 괄약근(sphincter) 조이기 운동을 통하여 두덩꼬리근(pubococcygeus muscle)을 강화하여 여성의 경우 질-회음(vagina-perineum) 주위 근육 의 탄력과 수축성을 증진시킬 수 있으며, 골반 주위 근육의 정상 기 능을 촉진시키고 골반 내부 장기를 정상 위치로 되돌리고 유지할 수 있는 체계적인 골반바닥근주위 근육들을 강화 시키는 운동이다. ${ }^{3}$ 이 와 같이 골반바닥근은 가장 기본적으로 골반 장기들 주위를 근막으 로 감싸고 있어 수축을 통하여 생식기 및 내부 장기들을 안쪽으로 들 어 올려 특히 요실금과 관련된 배뇨 및 배변조절을 담당하는 괄약근 강화에 쓰이는 근육으로 많이 알려져 있으나, 골반바닥근은 골반 강 (pelvic cavity)의 지지면을 형성하는 복합 근육으로서 자세조절, 배 내 압(intra-abdominal pressure) 조절 그리고 배설조절 등에 기여하는 근 육인 동시에 몸통 중심부의 근력 및 안정화를 위한 중요한 근육으로 배곧은근(rectus abdominis), 배속빗근(internal oblique), 배바깥빗근 (external oblique), 배가로근(transversus abdominis)과 같은 배 깊은 근 육들 그리고 깊은 척추 내재근(intrinsic muscle)들과 함께 서로 조화 를 이루어 수축하고 구조적인 위치로 인하여 날숨(expiration) 시 호흡 보조근의 역할로도 알려져 있다.45

골반바닥근이 호흡에 기여하는 기전은 들숨(inspiration)시 가로막 (diaphragm)의 수축으로 대기압 보다 낮은 폐의 압력에 의하여 외부 공기가 폐로 들어올 때 골반바닥근은 이완하여 아래 방향으로 움직 이면서 내부 장기가 가로막의 수축을 방해하지 않도록 돕는 반면에 날숨(expiration)시에는 골반바닥근이 수축하면서 위 방향으로 움직 여 외부로 공기가 빠져나갈 수 있도록 폐를 압박해주는 호흡 보조기 능도 있다고 하였다. ${ }^{7}$ 또한 골반바닥근은 깊은 배근육들과 협력 수 축을 통하여 배 내압을 증가시킴으로써 가로막을 위 방향으로 밀어 
올려서 강한 날숨을 발생시키기도 한다고 하였다. 따라서 골반바닥근 은 가로막 및 깊은 배 근육들과 함께 배 내압을 조절하면서 직접 또는 간접적으로 호흡에 관여하는 기능을 가지고 있는 근육이다. 기존수많 은 선행 연구들을 통해서도 케겔 운동을 통한 골반바닥근의 강화와 가 로막 그리고 폐활량의 관계에 있어 밀접한 연관이 있다는 것을 보고하 였다.7 예를 들면 수의적인 골반바닥근의 수축은 증가하는 배 내압을 통하여 가로막, 배 깊은 근육들에 영향을 주어 결과적으로 폐활량의 증 가뿐아니라근활성도나근육 두께의 증가를 확인하였다.9-13

나아가 골반바닥근을 강화하는 케겔 운동은 언제 어디서든 시행 할 수 있다는 장점을 통하여 일상생활에서 이루어지는 다양한 자세 즉 선 자세(standing), 앉은 자세(sitting) 그리고 누운 자세(supine) 등에 서 실시할 수 있다고 하였으며, 특히 선 자세 또는 앉은 자세에서 골반 바닥근이 강력하게 수축한다고 하였다.14,15 이러한 장점에도 불구하 고 기존 선행연구들은 케겔 운동을 할 때 가장 기본적인 자세인 바로 누운 자세에서 무릎을 $90^{\circ}$ 굽힘(hooklying) 자세를 가장 많이 활용하 고 있다.9-11 따라서 다양한 자세에서 실시한 케겔 운동을 통하여 폐활 량을 확인한 논문은 부족한 실정이므로 본 연구는 건강한 20대 남녀 대학생들을 대상으로 기존 선행 연구의 운동 방법을 본 연구에 맞게 수정하여, ${ }^{16,17}$ 가장 기본적으로 사용되는 바로 누운 자세에서 무릎을 $90^{\circ}$ 굽힘 자세와 의자에 바로 앉은 자세에서 케겔 운동을 실시하여 폐활량을 비교 및 분석하여 호흡 물리치료의 자세적인 측면에서 일 상 생활에서 이루어지는 다양한 자세 중 보다 효과적인 케겔 운동 자 세를 확인하고 이를 기초로 케겔 운동의 자세와 폐활량과의 관계를 확인하고자 진행하였다.

\section{연구 방법}

\section{1. 연구대상}

본 연구는 부산광역시 D대학교에 재학중인 건강한 남녀 대학생들 을 대상으로 실험 전에 연구의 목적과 방법에 대해 충분히 설명을 듣 고 자발적으로 동의한 자를 대상으로 17 명의 대상자들(남자 7명, 여 자 10 명)을 선정하였다. 대상자들의 선정 기준은 근육뼈대계 질환이 없는 자, 폐기능의 선천적인 문제가 없는 자, 최근 6 개월 또는 과거 호 흡기 질환의 진단 및 수술을 경험하지 않은 자, 운동에 대한 설명을 듣고 운동 수행이 가능하고 근력의 제한이 없는 자로 하였다. 대상자 들의 일반적인 특성은 Table 1 과 같다.

Table 1. General characteristics of subjects

\begin{tabular}{lc}
\hline Variables & Value \\
\hline Age $(\mathrm{yr})$ & $21.4 \pm 12.5$ \\
Height $(\mathrm{cm})$ & $166.5 \pm 8.4$ \\
Weight $(\mathrm{kg})$ & $61.1 \pm 12.4$ \\
\hline
\end{tabular}

\section{2. 실험방법}

1) 측정도구

(1) 폐활량 측정기

폐활량을 측정하기 위하여 들숨과 날숨량을 생리학적으로 측정하 는 폐활량 측정기(Pony FX, Cosmed, Italy)를 사용하였다(Figure 1). 본 연구의 폐활량 측정 변수로는 최대 수의 환기량(maximum voluntary ventilation)을 측정하였다. 최대 수의 환기량은 종합적인 폐기능을 평 가할 수 있는 지표로 기도(air way)와 호흡근, 폐, 가슴 안(intrathoracic) 의 탄성 등 호흡계 전체에 대한 종합적인 평가를 하는데 유용하게 사 용된다. ${ }^{9}$ 본 연구에서의 폐활량 측정방법은 대상자들에게 편안하게 의자에 걸터 앉으라고 지시하고 코마개로 코를 막고 우세손으로 폐 활량 기계를 잡고 입 주위로 바람이 빠지지 않게 마우스피스를 입술 로 반 이상 물게 하였으며 폐활량 측정 시 발생할 수 있는 몸통의 대 상작용에 대해서도 충분한 설명을 실시하였다(Figure 2). 또한 최대 수의 환기량은 1 분에 90-110회 비율로 가능한 빨리 최대한 들이 마시 고 최대한 내쉬는 호흡을 12 초간 유지할 수 있도록 지시하였으며 본 실험 전에 각 대상자들에게 충분한 설명과 연습을 진행하였다. 1 회 측정 후 30 초가량 휴식시간을 제공한 뒤 같은 방법으로 3 회 측정하 여 평균값을 채택하였다.

\section{2) 실험과정}

먼저 모든 대상자들에게 방광을 비우게 한 뒤 의자에 바로 앉은 자세 에서 폐활량 측정 방법에 따라 최대 수의 환기량을 3 회 측정하여 평 균값을 채택하였다. 본 연구에서 실시한 케겔 운동의 절차는 다음과 같다. 대상자들에게 무릎을 $90^{\circ}$ 굽힘 한 바로 누운 편안한 자세에서

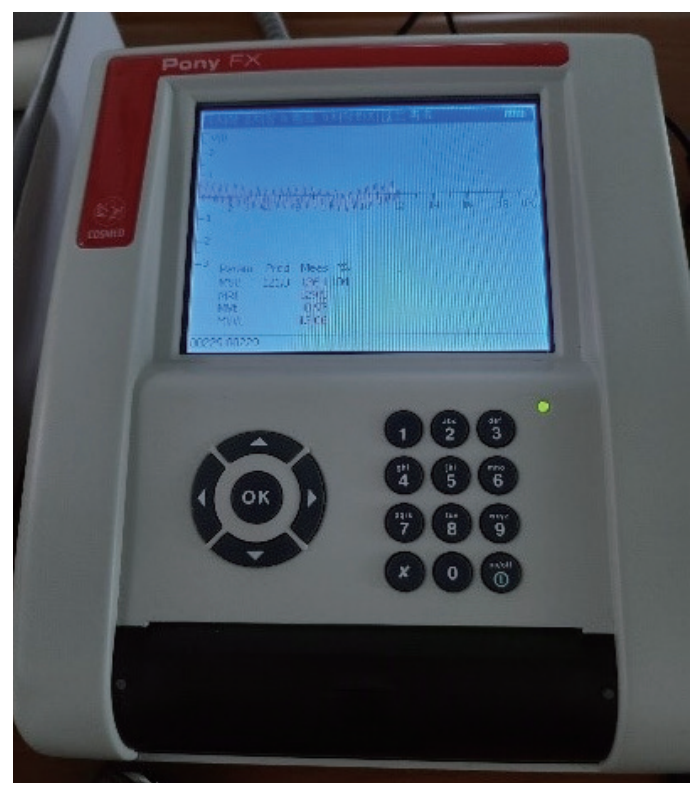

Figure 1. Measuring equipment (spirometer). 


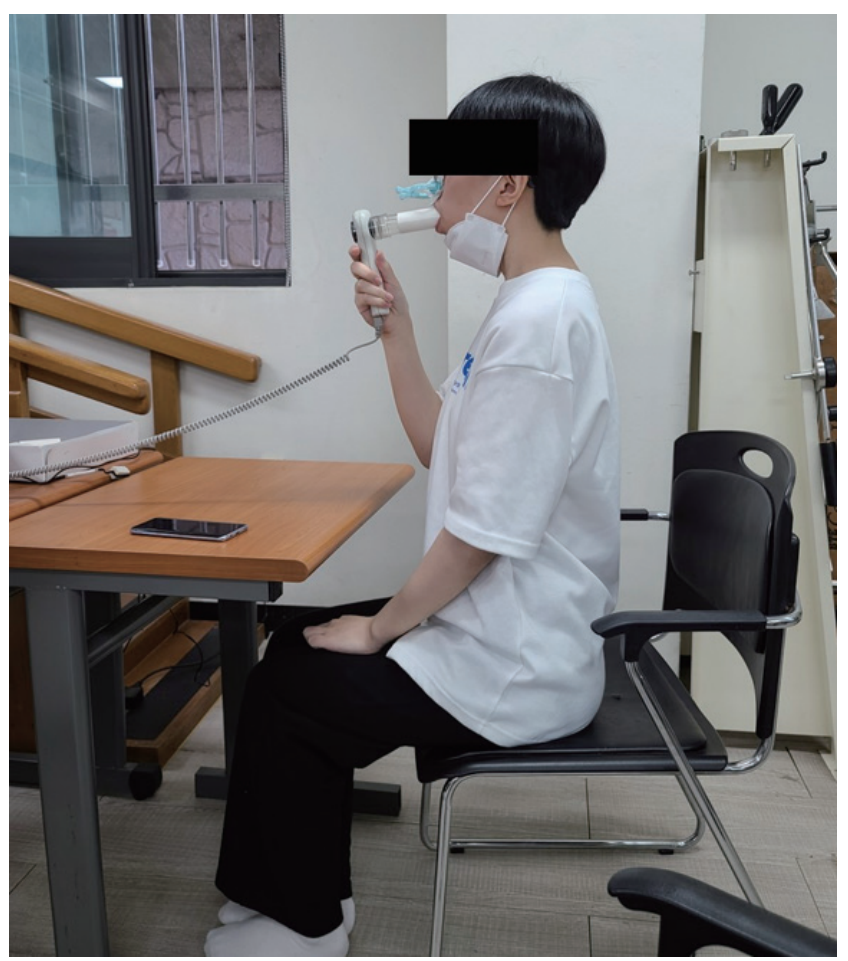

Figure 2. Measuring position (spirometry position before and after exercise).

깊은 호흡을 1-2번 하도록 지시하였다. 그 다음 몸을 이완하여 회음 부 주위 근육에 집중할 수 있도록 하고 회음부 주위 근육을 수축할 때 호흡은 편안하게 유지하며 배꼽이나 배 주위 근육의 강력한 수축 이나 골반의 움직임을 예방하도록 지시하였다. 골반바닥근 주위 근 육을 안쪽을 끌어당긴다는 느낌을 통하여 골반바닥근의 수축을 충 분히 연습하도록 하였다. 본 연구의 또 다른 자세인 의자에 바로 앉은 자세에서도 위와 같은 방법으로 진행하였다. ${ }^{14}$ 케겔 운동에 대해서 충분한 숙지를 한 후 5 분간의 휴식을 제공하였다. 17 명의 대상자들에 게 적용한 앉은 자세 그리고 바로 누운 자세에서의 케겔 운동 순서는 학습 효과를 배제하기 위하여 대상자들이 직접 제비 뽑기를 통해서 나오는 순서대로 무작위로 운동을 진행하였다. 자세 변화에 따른 운 동의 휴식시간은 5 분을 제공하였다. 각 운동 휴식시간 후에 폐활량 을 3 회 측정하여 평균값을 채택하였다.

본 연구에서의 케겔 운동은 기존 선행연구의 수축시간을 수정 및 보완하여 수축시간은 10 초, 휴식시간은 5 초로 10 회 1세트로 하여 5 세트 실시하였다. 각 세트 마다 휴식시간은 1 분을 제공하였다. ${ }^{18}$

\section{3) 자료분석}

자료의 분석은 SPSS version 22.0 프로그램을 사용하였다. 자료의 정 규성 검정은 Shapiro-Wilk로 확인하였으며 자세에 따른 폐활량을 비 교하기 위하여 일원 배치 분산분석(one way repeated ANOVA)을 사용
Table 2. Comparison of vital capacity according to the position

$(n=17)$

\begin{tabular}{cccccc}
\hline & \multicolumn{4}{c}{ Position } & \\
\cline { 2 - 4 } & $\begin{array}{c}\text { Pre Kegel } \\
\text { exercise }\end{array}$ & Post sitting & Post hooklying & P \\
\hline MV (L) & $116.01 \pm 40.78$ & $127.83 \pm 43.66$ & $128.86 \pm 40.64$ & 19.601 & $<0.001^{*}$
\end{tabular}

${ }^{*} p<0.05$

MV: maximum voluntary ventilation, Post sitting: Kegel exercise in a sitting position, Post hooklying: Kegel exercise in a hooklying position.

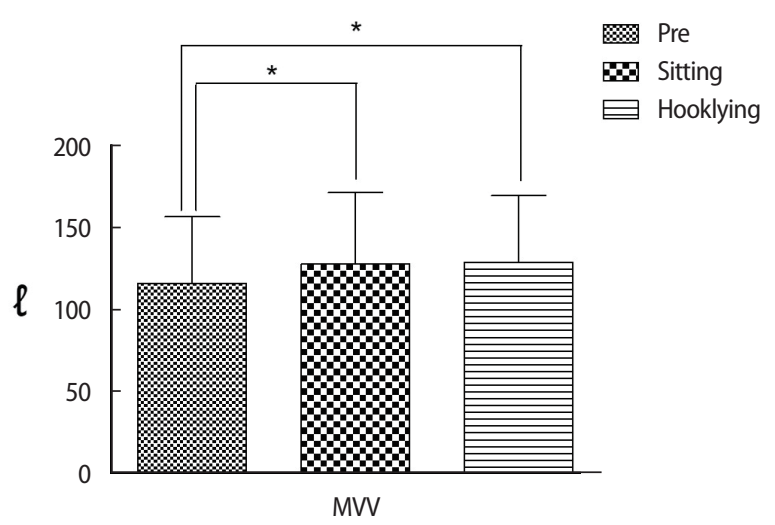

Figure 3. Comparison of maximum voluntary ventilation according to the position.

하였다. 사후분석으로는 본페로니(Bonferroni)를 이용하였다. 통계학 적인 유의수준은 0.05 로 하였다.

\section{결 과}

케겔 운동을 실시하기 전보다 앉은 자세와 무릎을 $90^{\circ}$ 굽힌 바로 누 운 자세에서 실시한 케겔 운동 후 측정한 최대 수의 환기량에서 유의 한 차이가 나타났다 $(\mathrm{p}<0.05)$ (Table 2). 즉 케겔 운동 전과 의자에 바로 앉은 자세에서 실시한 케겔 운동의 폐활량 비교 그리고 케겔 운동 전 과 무릎 $90^{\circ}$ 굽힌 바로 누운 자세에서 실시한 케겔 운동의 폐활량 비 교에서 유의한 차이가 있었으나 $(\mathrm{p}<0.05)$, 사후분석 결과 의자에 바로 앉은 자세에서 실시한 케겔 운동과 무릎 $90^{\circ}$ 굽힌 바로 누운 자세에 서 실시한 케겔 운동의 폐활량 비교에서는 유의한 차이가 없었다 ( $>0.05)$ (Figure 3).

\section{고 찰}

일반적으로 골반바닥근은 배와 골반 내장(pelvic viscera)을 지지하며 기침이나 호흡할 때 증가하는 배 내압에 대항하여 방광 목(bladder neck)의 위치 및 요도와 항문 조절 뿐 아니라 가로막과 함께 호흡하는 동안 같은 움직임을 보이며 특히 깊은 배 근육들과 함께 협력 수축을 
통한 호흡에 기여한다고 하였다.1920 또한 기존 선행 연구들에서 골반 바닥근, 가로막 그리고 배 근육들과 협력 수축을 통하여 호흡에 관여 한다고 보고하였다.21-23 실제로 젊은 여대생을 대상으로 실시한 케겔 운동을 통하여 골반바닥근의 강화가 폐기능의 증가를 확인할 수 있 었고 ${ }^{910}$ 더불어 호흡에 있어 가장 중요한 기능을 하는 가로막과 골반 바닥근의 상호작용을 확인하고 동시에 배 근육들의 활성도와 함께 폐기능의 증가를 확인하였다."

본 연구 결과에서도 케겔 운동을 시행하기 전보다 의자에 바로 앉 은 자세와 무릎을 $90^{\circ}$ 굽힌 바로 누운 자세에서 케겔 운동을 하고 난 후 폐기능의 증가를 확인하였다. 이는 골반바닥근의 수축은 배 내압 의 증가로 인한 1 차적인 가로막의 자극과 동시에 날숨의 작용 근인 배 근육들과의 협력 수축을 통한 결과라고 생각된다. 위와 같은 결과 는 골반바닥근의 수축이 배가로근과 배속빗근의 강화를 확인한 선 행 연구 와도 같은 맥락으로 생각할 수 있다.,11

하지만 본 연구에서 앉은 자세와 무릎을 $90^{\circ}$ 굽힌 바로 누운 자세 에서 실시한 케겔 운동에 따른 폐활량 비교에서는 유의한 차이가 없 었다. 단순히 골반바닥근의 수축력을 확인한 기존 선행연구인 항문 압력 측정법(manometry testing)에서 4 가지 자세 중 선 자세에서 골반 바닥근의 가장 높은 수축을 확인할 수 있었으며 그 다음 앉은 자세, 바로 누운 자세 그리고 무릎을 굽힌 바로 누운 자세순으로 나타났 다. ${ }^{16}$ 위와 같은 결과는 선 자세가 중력에 가장 영향을 많이 받고 이러 한 영향이 골반바닥근 수축력의 증가로 나타났다고 하였다. 또 다른 연구에서는 디지털 근력 검사(digital muscle testing scale)를 이용한 골 반바닥근의 수축력을 확인한 결과에서 앉은 자세, 선 자세, 무릎 굽 힌 자세 그리고 바로 누운 자세순으로 골반바닥근의 수축력이 나타 났다. 그리고 폐활량과 연계하여 앉은 자세와 무릎을 굽힌 누운 자세 에서의 폐활량을 비교한 연구에서는 앉은 자세에서 높은 폐활량의 결과가 나타났다. 이러한 결과는 앉은 자세는 무릎을 굽힌 누운 자세 보다는 가로막과 배의 탄력이나 배 주위 근육들의 팽창요소가 횔씬 크고 또한 폐를 통한 압력의 기계적인 이점을 제공하며 앉은 자세에 서 기도의 저항이 감소하기 때문이라고 하였다. ${ }^{24}$

그러나 본 연구에서는 의자에 바로 앉은 자세와 무릎을 $90^{\circ}$ 굽힌 바로 누운 자세에서 각각 케겔 운동을 실시한 뒤 의자에 바로 앉은 자세에서 폐활량을 비교하였으며 비교 결과 $1 \mathrm{~L}$ 가량 무릎을 $90^{\circ}$ 굽힌 바로 누운 자세에서 실시한 케겔 운동의 폐활량이 높게 나타났다. 위 와 같은 결과는 자세에 따른 폐활량 비교에서 가로막에 의하여 증가 하는 배 내압이 바로 누운 자세보단 선 자세나 앉은 자세가 훨씬 크 며 가슴내 혈액 부피(intra thoracic blood volume)로 인한 기도의 폐쇄 에 영향을 덜 받는 자세에 따른 폐활량을 비교한 선행 연구와의 방법 이 달랐다. 더불어 단순히 중력의 노출에 의한 자세에 따른 골반바닥 근의 수축력을 확인한 연구와도 달리 본 연구는 케겔 운동의 특성상
회음부 주위 근육들을 수축하기 위해서는 집중도가 필요로 하는데 본 연구 결과 의자에 바로 앉은 자세에서 실시한 케겔 운동은 약 15 분 가량 앉은 자세를 유지하다 보니 본 실험의 앉은 자세와 누운 자세 변화에 따른 피로도를 생각하여 휴식시간을 제공함에도 불구하고 바로 누운 자세보다는 앉은 자세에서 자세 유지근들(anti-gravity muscle)의 피로도 증가와 무릎을 $90^{\circ}$ 굽힌 바로 누운 자세에서 실시 한 골반바닥근의 수축에 대한 대상자들의 집중력이 조금 더 좋았던 것으로 파악된다. ${ }^{24,25}$

따라서 본 연구는 건강한 20대 대학생들을 대상으로 케겔 운동을 실시하기 전보다 앉은 자세와 무릎을 $90^{\circ}$ 굽힌 바로 누운 자세에서 실시한 케겔 운동 후의 폐활량 검사에서 유의한 차이를 확인하였으 나 두가지 자세를 비교한 사후분석 결과에서는 유의한 차이를 확인 하지 못하였다. 비록 본 연구가 기존 선행연구들의 비교와는 달리 자 세에 따른 케겔 운동을 통한 폐활량을 비교한 결과에서는 유의한 차 이가 없었지만 본 연구에서 나타난 제한점들 즉 본 연구에서는 케겔 운동 후에 즉각적인 효과를 확인하였기에 이를 보완하여 중. 장기적 인 측면에서의 중재적용 기간 및 적용 시간의 증가, 적은 대상자수그 리고 본 연구의 케겔 운동시에 대상자들이 보다 집중할 수 있는 실험 환경 등을 수정 보완한다면 보다 유의한 차이가 나타날 것으로 생각 한다. 더욱이 본 연구를 토대로 보다 다양한 자세에서 실시한 케겔 운 동과 폐활량과의 효과를 입증하고 임상적으로 적용할 수 있는 다양 한 연구의 방향성을 제시하고자 한다. 또한 본 연구에서 나타난 제한 점을 보완하여 보다 더 다양한 자세에서 실시한 케겔 운동이 폐활량 뿐 아니라 호흡 근육의 활성도 및 두께와의 관계도 알아보고자 한다.

\section{REFERENCES}

1. Lemos NL, Auge AP, Lunardelli JL et al. Validation of the pelvic organ prolapse quantification index (POP-Q-I): a novel interpretation of the POP-Q system for optimization of POP research. Int Urogynecol J Pelvic Floor Dysfunct. 2008;19(7):995-7.

2. Mørkved S, Bø K. The effect of postpartum pelvic floor muscle exercise in the prevention and treatment of urinary incontinence. Int Urogynecol J Pelvic Floor Dysfunct. 1997;8(4):217-22.

3. Marshall PW, Murphy BA. Core stability exercises on and off a swiss ball. Arch Phys Med Rehabil. 2005;86(2):242-9.

4. Hodges PW, Eriksson AE, Shirley D. Intra-abdominal pressure increases stiffness of the lumbar spine. J Biomech. 2005;38(9):1873-80.

5. Hodges PW, Sapsford R, Pengel LH. Postural and respiratory functions of the pelvic floor muscles. Neurourol Urodyn. 2007;26(3):362-71.

6. Neumann P, Gill V. Pelvic floor and abdominal muscle interaction: EMG activity and intra-abdominal pressure. Int Urogynecol J Pelvic Floor Dysfunct. 2002;13(2):125-32.

7. Talasz H, Kofler M, Kalchschmid E et al. Breathing with the pelvic floor? correlation of pelvic floor muscle function and expiratory flows in 
healthy young nulliparous women. Int Urogynecol J. 2010;21(4):475-81.

8. Campbell EJ, Green JH. The expiratory function of the abdominal muscles in man; an electromyographic study. J Physiol. 1953;120(3):409-18.

9. Park HK. Effects of pelvic floor muscle contraction on pulmonary function and diaphragm activity. Silla University. Dissertation of Master's Degree. 2014.

10. Han D, Ha M. Effect of pelvic floor muscle exercises on pulmonary function. J Phys Ther Sci. 2015;27(10):3233-5.

11. Park HK, Han DW. The effect of the correlation between the contraction of the pelvic floor muscles and diaphragmatic motion during breathing. J Phys Ther Sci. 2015;27(7):2113-5.

12. Hodges PW, Sapsford R, Pengel LH. Postural and respiratory functions of the pelvic floor muscles. Neurourol Urodyn. 2007;26(3):362-71.

13. Goldish GD, Quast JE, Blow JJ et al. Postural effects on intra-abdominal pressure during valsalva maneuver. Arch Phys Med Rehabil. 1994;75 (3):324-7.

14. Aslan E, Komurcu N, Beji NK et al. Bladder training and kegel exercises for women with urinary complaints living in a rest home. Gerontology, 2008;54(4):224-31.

15. Hodges PW, Sapsford R, Pengel LH. Postural and respiratory functions of the pelvic floor muscles. Neurourol Urodyn, 2007;26(3):362-71.

16. Gameiro MO, Miraglia L, Gameiro LFO et al. Pelvic floor muscle strength evaluation in different body positions in nulliparous healthy women and its correlation with sexual activity. Int Braz J Urol. 2013; 39(6):847-52.

17. Frawley HC, Galea MP, Phillips BA et al. Reliability of pelvic floor mus- cle strength assessment using different test positions and tools. Neurourol Urodyn. 2006;25(3):236-42.

18. Kashanian M, Ali SS, Nazemi M et al. Evaluation of the effect of pelvic floor muscle training (PFMT or Kegel Exercise) and assisted pelvic floor muscle training (APFMT) by a resistance device (Kegelmaster Device) on the urinary incontinence in women: a randomized trial. Eur J Obstet Gynecol Reprod Biol. 2011;159(1):218-23.

19. Morgan DM, Kaur G, Hsu Y et al. Does vaginal closure force differ in the supine and standing positions?. Am J Obstet Gynecol. 2005;192 (5):1722-8.

20. Howard D, Miller JM, Delancey JO et al. Differential effects of cough, valsalva, and continence status on vesical neck movement. Obstet Gynecol. 2000;95(4):535-40.

21. Hodges PW, Sapsford R, Pengel LH. Postural and respiratory functions of the pelvic floor muscles. Neurourol Urodyn. 2007;26(3):362-71.

22. Bø K, Lilleås F, Talseth T et al. Dynamic MRI of the pelvic floor muscles in an upright sitting position. Neurourol Urodyn. 2001;20(2):167-74.

23. Sapsford R. Rehabilitation of pelvic floor muscles utilizing trunk stabilization. Man Ther. 2004;9(1):3-12.

24. Sudan DS, Singh H. A comparative study to evaluate the effect of crook lying position versus sitting position on forced vital capacity (FVC) in healthy individuals. J Clin Diagn Res. 2014;8(2):17-9.

25. Melam GR, Buragadda S, Alhusaini A et al. Effect of different positions on FVC and FEV1 measurements of asthmatic patients. J Phys Ther Sci. 2014;26(4):591-3. 